\title{
Analytical study of adolescent pregnancies at a tertiary care centre
}

\author{
Shubha Srivastava ${ }^{1 *}$, Madhuri Chandra ${ }^{2}$, Umesh Kumar Singh ${ }^{3}$ \\ ${ }^{1}$ Department of Obstetrics and Gynecology, Gandhi Medical College; ${ }^{2}$ Mahavir Institute of Medical Sciences, Bhopal, \\ Madhya Pradesh, India \\ ${ }^{3}$ District Hospital, Singrauli, Bhopal, Madhya Pradesh, India
}

Received: 11 February 2017

Accepted: 16 February 2017

*Correspondence:

Dr. Shubha Srivastava,

E-mail: drshubhasrivastava76@gmail.com

Copyright: ( $)$ the author(s), publisher and licensee Medip Academy. This is an open-access article distributed under the terms of the Creative Commons Attribution Non-Commercial License, which permits unrestricted non-commercial use, distribution, and reproduction in any medium, provided the original work is properly cited.

\section{ABSTRACT}

Background: According to World Health Organization, about 16 million girls aged 15 to 19 and some 1 million girls under the age of 15 give birth every year. Teenage pregnancies have shown association with higher risks of prematurity, low birth weight, preeclampsia and anaemia as compared to adult pregnancies. The present study was analytical study of pregnant adolescent girls and feto-maternal outcome at a tertiary care centre.

Methods: Girls between 10 to19 years, who attended the antenatal clinic and/or who were admitted in the hospital while pregnant or during labour were included in the study. A questionnaire along with detailed history and examination were done. Adolescents who were admitted for confinement, details of labour and mode of delivery were noted. The newborn was assessed in context of prematurity, IUGR or any other complications and referral to NICU.

Results: Of the 1870 adolescent girls attending the OPD, 1234 (65.98\%) were pregnant. There were $429(4.02 \%)$ teenage deliveries in the institute during the study period. The girls were mostly married, older teenagers and primigravidas. The use of contraception was poor and awareness regarding antenatal care was lacking. The most common risk factor was anemia. The other risk factors included HDP, preterm labor, PROM, IUGR, hemorrhage and previous LSCS.

Conclusions: Early childbearing increases the risks for both mothers and their newborns. A delay in marriage givesadolescents opportunities for higher education, thus empowers them. Sex education should be a part of the school curriculum. Good antenatal care may reduce complications of teenage pregnancy.

Keywords: Adolescent pregnancy, Analytical study, Obstetric outcome

\section{INTRODUCTION}

Teenage pregnancy is one of the most important social and medical problems faced by our society today. ${ }^{1}$ According to World Health Organization, about 16 million girls aged 15 to 19 and some 1 million girls under the age of 15 give birth every year, mostly in low- and middle-income countries. Every year, 3 million girls aged 15 to 19 undergo unsafe abortions. ${ }^{2}$ The risk of death due to pregnancy-related causes is double among women aged 15-19 compared to women in their twenties. ${ }^{3}$
In contrast to the western countries, most of the teenage pregnancies in India occur within the confines of marriage and tend to be welcomed by family members and society. Despite the legal age for marriage of girls being 18 years, $47.4 \%$ of women in India were child brides, a higher proportion of them being in rural areas (NHFS III 2005-2006).

Marriage at a young age has serious psychological and physical bearing on the young bride. These girls usually 
have very little knowledge about STDs, RTIs and contraception. There is also a barrier in obtaining such information due to hesitancy on the part of the girls or lack of help or both. As a result they are exposed to many serious health issues and unwanted and unplanned pregnancies. This also leads to not just physical harm but also emotional and mental stress.

These pregnancies are usually amongst the most deprived sections of the society where illiteracy and poor economic status play big roles. These young girls are often neglected. The combined burden of physical growth and pregnancy, lack of antenatal care and the high risk nature of pregnancy all contribute to adverse fetomaternal outcome. Teenage pregnancies have shown association with higher risks of prematurity, low birth weight, preeclampsia and anaemia as compared to adult pregnancies. ${ }^{4,5}$ Long term follow up studies have shown that the children born to teenage mothers are at higher risk and are usually plagued by intellectual, language, and socio-emotional delays. ${ }^{6}$ The female child of an adolescent has higher risk of becoming pregnant herself as a teenager. ${ }^{7}$ Also due early initiation of sexual activity and multiple pregnancies these girls become high risk for cervical cancer.

The present study was an analytical study of adolescent pregnancies at a tertiary care centre.

\section{METHODS}

The study was conducted in the Department of Obstetrics and Gynaecology, Gandhi Medical College, Bhopal, Madhya Pradesh, India. The study was conducted over a period of one year and all pregnant adolescents who were willing to participate were included. The study was conducted after prior approval from the ethical committee. It was a hospital based analytical study.

Adolescent girls between 10 to19 years, who attended the antenatal clinic and/or who were admitted in the hospital while pregnant or during labour were included in the study. In the antenatal clinic a detailed history and examination were done. Any risk factors identified and relevant investigations done. A questionnaire was given to study the demographic characteristics of the adolescent girl and awareness and access to antenatal care.

The adolescent girls who were admitted during pregnancy or labour were also included. Along with the questionnaire, history and examination, complications with which admitted, labour and delivery and any significant event during the stay in hospital were taken into account.

The newborn was assessed in context of prematurity, IUGR or any other complications and referral to NICU was noted. The information was collated and analyzed by simple proportions.

\section{RESULTS}

A total of 37551 patients attended the OPD of Sultania Zanana Hospital, Bhopal during the course of study and of these $1870(4.97 \%)$ were adolescent girls. The total indoor admission was 16484 of which 455 (2.7\%) were adolescent girls. Of the 1870 adolescent girls attending the OPD, $1234(65.98 \%)$ were pregnant and presented to the antenatal clinic, $4(0.21 \%)$ girls wanted medical termination of pregnancy and registered themselves in the family planning clinic and the rest 632 (33.7\%) girls attended the OPD for gynaecological problems (Table 1).

Table 1: Adolescent girls attending the hospital.

\begin{tabular}{|llll|}
\hline OPD & $\begin{array}{l}\text { Number of } \\
\text { girls }\end{array}$ & IPD admission & $\begin{array}{l}\text { No. of } \\
\text { girls }\end{array}$ \\
\hline $\begin{array}{l}\text { Antenatal } \\
\text { clinic }\end{array}$ & $1234(65.98 \%)$ & During labour & 429 \\
\hline $\begin{array}{l}\text { Gynae } \\
\text { OPD }\end{array}$ & $632(33.7 \%)$ & $\begin{array}{l}\text { Pregnancy } \\
\text { complications }\end{array}$ & 05 \\
\hline $\begin{array}{l}\text { Family } \\
\text { planning } \\
\text { clinic }\end{array}$ & $04(0.21 \%)$ & Abortion & 06 \\
\hline Total & $1870(100 \%)$ & MTP & 04 \\
\hline & & $\begin{array}{l}\text { Gynaecological } \\
\text { problem }\end{array}$ & 11 \\
\hline & & Total & 455 \\
\hline
\end{tabular}

The total number of adolescent girls admitted was 455 . Of these 444 girls were admitted for obstetrical reasons. The total number of deliveries in the hospital during the study period was 10650. Of these 429 (4.02\%) were among teenage girls. 5 girls were admitted for pregnancy complications and were managed conservatively.

There were 6 adolescent girls with inevitable/incomplete abortion. Medical termination of pregnancy was performed on 4 girls and the rest were admitted for gynaecological problems (Table 1).

A total of 1234 girls attended the antenatal clinic. All were between 17-19 years of age. 1232 girls were married and two were unmarried. 1225 (99\%) were primigravidas and 9 were multigravidas. Most of the primigravidas $(81 \%)$ were pregnant with in first year of marriage. Most of the adolescents $(97 \%)$ claimed to have used some form of contraception. The rest $3 \%$ had never used any contraception. The contraceptives used were barrier or combined oral contraceptive pills, usually during the first few months of marriage.

Maximum girls (85\%) were from urban ares. Most of these girls had infrequent antennal visits. Only 46 (3.7\%) had visited the hospital three or more times. Level of 
education was poor with $53(4.2 \%)$ girls being uneducated and $827(67 \%)$ girls having primary schooling (Table 2).

The risk factors identified during ANC visits were anaemia $(27.3 \%)$, hypertensive disorders of pregnancy $(3.5 \%)$ and urinary tract infection (1.5\%). 1 girl had ectopic pregnancy and 1 had vesicular mole. 5 girls had spontaneous abortion.

Table 2: Demographic characteristics of adolescent girls attending antenatal clinic and/or admitted in hospital.*

\begin{tabular}{|c|c|c|}
\hline & OPD & IPD \\
\hline \multicolumn{3}{|l|}{ Age } \\
\hline$<17$ years & 00 & 00 \\
\hline$>17$ years & 1234 & 444 \\
\hline \multicolumn{3}{|l|}{ Marital status } \\
\hline Married & $1232(99.98 \%)$ & $442(99.5 \%)$ \\
\hline Unmarried & $02(0.02 \%)$ & 02 \\
\hline \multicolumn{3}{|l|}{ Parity } \\
\hline Primigravida & $1225(99.2 \%)$ & $435(97.9 \%)$ \\
\hline Multigravida & $09(0.8 \%)$ & $09(2.1 \%)$ \\
\hline $\begin{array}{l}\text { Duration of } \\
\text { marriage in } \\
\text { primigravidas** }\end{array}$ & $\mathrm{n}=1223 * *$ & $\mathrm{n}=433 * *$ \\
\hline$<1$ year & $1003(82 \%)$ & 377 \\
\hline $1-2$ years & $157(12.8 \%)$ & 36 \\
\hline$>2$ years & $63(5.1 \%)$ & 20 \\
\hline \multicolumn{3}{|l|}{ Contraceptive use } \\
\hline Ever used & $1097(88.9 \%)$ & $379(85.3 \%)$ \\
\hline Never used & $137(11.1 \%)$ & $65(14.7 \%)$ \\
\hline \multicolumn{3}{|l|}{ Residence } \\
\hline Urban & $1050(85 \%)$ & $357(80.4 \%)$ \\
\hline Rural & $184(15 \%)$ & $87(19.6 \%)$ \\
\hline \multicolumn{3}{|l|}{ Antenatal visits } \\
\hline$<3$ & $1188(96.2 \%)$ & $352(79.2 \%)$ \\
\hline$>3$ & $46(3.8 \%)$ & $77(20.8 \%)$ \\
\hline \multicolumn{3}{|l|}{ Educational status } \\
\hline Uneducated & $53(4.2 \%)$ & $23(5.1 \%)$ \\
\hline Primary school & $827(67 \%)$ & $193(43.4 \%)$ \\
\hline High school & $191(15.4 \%)$ & $152(34.2 \%)$ \\
\hline Senior sec./ more & $163(13.2 \%)$ & $76(17.1 \%)$ \\
\hline
\end{tabular}

*Admitted during pregnancy and in labour ; **2 girls were unmarried.

One each tested positive for malaria and HIV. 59 girls had other problems such as respiratory tract infection, jaundice, h/o tuberculosis, post-polio paralysis etc (Table 3).

A total of 429 adolescent girls were admitted for confinement. Of them $275(64.1 \%)$ delivered without complications.

Anemia was present in 183 (42.6\%) adolescents. $28(6.5 \%)$ girls had hypertensive disorders of pregnancy.
Amongst them, 12 patients had eclampsia. Preterm labour pains and premature rupture of membranes was seen in $42(9.7 \%)$ and $(6.5 \%)$ respectively.

Table 3: Risk factors identified in pregnant adolescents attending antenatal clinic.

\begin{tabular}{|lll|}
\hline Risk factors & & \\
\hline Anemia & 337 & $27.30 \%$ \\
\hline HDP & 44 & $3.50 \%$ \\
\hline H. mole & 1 & $0.08 \%$ \\
\hline Ectopic & 1 & $0.08 \%$ \\
\hline UTI & 19 & $1.50 \%$ \\
\hline Abortion & 5 & $0.40 \%$ \\
\hline Malaria & 1 & $0.08 \%$ \\
\hline HIV + & 1 & $0.08 \%$ \\
\hline Others & 59 & $4.70 \%$ \\
\hline
\end{tabular}

Intra uterine growth retardation of fetus was noted in 27 $(6.5 \%)$ and $5(1.16 \%)$ had intrauterine fetal demise. 2 patients had congenital anomaly in fetus and both gave h/o consanguineous marriage. 3 patients had undergone LSCS previously.

Table 4: Risk factors/complications during labour.

\begin{tabular}{|lll|}
\hline Risk factors & & \\
\hline Anemia & 183 & $(42.6 \%)$ \\
\hline HDP & 28 & $(6.5 \%)$ \\
\hline Preterm & 42 & $(9.7 \%)$ \\
\hline PROM & 28 & $(6.5 \%)$ \\
\hline IUGR & 27 & $(6.5 \%)$ \\
\hline IUFD & 05 & $(1.16 \%)$ \\
\hline Oligohydranios & 04 & $(0.93 \%)$ \\
\hline Congenital anomaly & 02 & $(0.46 \%)$ \\
\hline Previous LSCS & 03 & $(0.69 \%)$ \\
\hline APH & 05 & $(1.16 \%)$ \\
\hline PPH & 04 & $(0.93 \%)$ \\
\hline Retained placenta & 01 & $(0.23 \%)$ \\
\hline Others & 16 & $(3.7 \%)$ \\
\hline
\end{tabular}

Antepartum hemorrhage was present in 5 patients (4 abruptio placentae and one placenta previa). Post-partum haemorrhage occurred in $4(0.93 \%)$ and one ended up with retained placenta (Table 4$)$.

More than $75 \%$ adolescent girls delivered vaginally and $103(24 \%)$ underwent LSCS. 3 patients had instrumental delivery. Blood and/ or blood product transfusion was done to $61(14.2 \%)$ adolescents.

ICU monitoring was required by $27(6.2 \%)$ and 2 patients were transferred to medical unit for acute renal failure and cerebrovascular accident. There were no maternal deaths. Preterm neonates were 42 (9.7\%), 27 (6.2\%) were small for date, and $5(1.16 \%)$ were still born. 31 $(7.2 \%)$ babies required NICU care, mostly for prematurity (Table 5). 
Table 5: Mode of delivery and feto-maternal outcome.

\begin{tabular}{|lllll|l|}
\hline Mode of delivery & \multicolumn{3}{c|}{ Fetal outcome } \\
\hline Vaginal delivery & $323(75.2 \%)$ & $\begin{array}{l}\text { Blood or blood product } \\
\text { transfused }\end{array}$ & $61(14.2 \%)$ & Preterm & $51(9.7 \%)$ \\
\hline LSCS & $103(24 \%)$ & ICU monitoring & $27(6.2 \%)$ & IUGR & $27(6.2 \%)$ \\
\hline Instrumental delivery & $03(0.7 \%)$ & Transfer to other department & $02(0.46 \%)$ & NICU admission & $31(7.2 \%)$ \\
\hline & & Maternal mortality & 00 & Still born & $05(1.16 \%)$ \\
\hline
\end{tabular}

\section{DISCUSSION}

South Asia along with Africa is the capital of teenage pregnancy. Among the South Asian countries, the recorded teenage pregnancy rate is highest in Bangladesh (35\%) followed by Nepal $(21 \%)$ and India $(21 \%){ }^{8}$ The present study was under taken to study the demographic profile and outcome of teenage pregnancy at the largest tertiary care centre in Madhya Pradesh, India.

A total of 1870 adolescent girls attended the OPD during the study period. $1238(66.2 \%)$ among them were pregnant, making pregnancy the most common reason for adolescent girls to attend the OPD. None of the girls was below 17 years of age. This is in accordance with other studies on teenage pregnancy where the subjects mainly belonged to the older teenage group. ${ }^{9,10}$ Majority of the girls were married indicating that teenage pregnancy in our society is mostly within the confines of marriage. Similar observations have been made by other studies in India. ${ }^{4,9,11}$ The pregnancies occurring out of wedlock are usually are not disclosed until late during the gestation and very few such pregnancies report to the hospitals due the issue of secrecy. As unwed mothers are not socially accepted in our society, these young females resort to unsafe abortions leading to high morbidity and mortality. ${ }^{12}$

The girls were mostly primigravidas $(99.2 \%)$ and $82 \%$ of the girls had conceived within first year of marriage. This was despite the fact that $88.89 \%$ girls claimed to have ever used some form of contraception. This reflects the lack and inconsistent use of contraceptive methods among the young population. Another fact which was highlighted during the study was peer pressure to have kids by the young girls early during their married life. According to a report of Ministry of Health and Family welfare, Govt. of India 2006, only $15 \%$ young men and women in 15-24 age group reported that they had received family life or sex education in school or through special program sponsored by the government or NGOs although they expressed the need. ${ }^{13}$

The girls were mostly from the urban areas. This may be because of the urban location of the hospital. At term, only $46(3.7 \%)$ girls had 3 or more antenatal visits. 880 $(71.3 \%)$ girls were either uneducated or had only primary education. This shows the lack of awareness regarding the importance of antenatal care. Lack of antenatal care during pregnancy is one of the main contributors to adverse feto-maternal outcome. In a study by Mahfouz et al it was concluded that pregnant teenagers were not a high-risk group if good prenatal care was provided and the pregnancy outcome was at par to women in their twenties. $^{14}$ Anemia and hypertensive disorders of pregnancy were the two main high risk factors identified during antenatal checkups as well as among adolescents admitted during labour. Similar findings were noted in many other studies. ${ }^{4,9,10,15,16}$ In India more than $50 \%$ of the pregnant women are anemic. Among the teenagers the added burden of pregnancy along with physical growth, lack of antenatal care and poor nutrition aggravate anaemia even more. Severe anemia during pregnancy significantly contributes to maternal mortality and morbidity. ${ }^{17}$ There is evidence that severe anemia also increases perinatal morbidity and mortality by causing intrauterine growth retardation and preterm delivery. ${ }^{18}$ Educating the young girls and good antenatal care may pave way to better outcome.

The teenage obstetric patients admitted during the study period, showed similar demographic characters as the ones attending antenatal clinic. They were older teenagers, mostly primigravidas, who had conceived with a year of marriage. The record showed poor antenatal care and low literacy. Santos et al in their study on teenage pregnancy found low birth weight and prematurity to be associated with low level of schooling, low number of prenatal visits, and late initiation of prenatal care. ${ }^{19}$ The most common risk factor among teenagers admitted for confinement was anemia. The other risk factors identified were hypertensive disorders of pregnancy, preterm labour, PROM, IUGR, IUFD, congenital anomaly in fetus.

$61(14.2 \%)$ of the young mothers required blood and /or blood product transfusion. $42(9.7 \%)$ had preterm deliveries, making it the second most common complication. 31 babies required NICU admission and 5 were stillborn. Many studies have reflected poor perinatal outcome in the form of preterm delivery, low birth weight, NICU admission and even perinatal mortality. ${ }^{4,9.10,20,21}$ In the large population-based study conducted in six large middle income countries, Althabe et al found that the risks of preterm birth and LBW were significantly higher among both early and older 
adolescents. ${ }^{22}$ Yasmin et al in their study concluded that low weight and prematurity were determining factors of fetal and neonatal death. ${ }^{23}$ In contrast Loppo et al in their study found that adolescents had lower rates of PROM, placenta previa, prolonged labour, breech presentation, among other complications. ${ }^{24}$ Althabe e al in their meta analysis found that there were neither clinical nor statistical significant differences in the risk of antepartum hemorrhage, postpartum hemorrhage, or maternal sepsis among adolescents 15-19 years and <15 years compared to adults 20-24 years. However, the risks of obstructed labour and hypertensive disorders were significantly lower among adolescents 15-19 years compared to adults 20-24 years. ${ }^{22} 103(24 \%)$ underwent LSCS and 3 had instrumental delivery. Some authors have reported increased operative deliveries while some had found significantly less operative interventions. The most common indication for caesarean section was fetal distress followed by cephalopelvic disproportion. Other studies have also found these to be the most common indications for operative deliveries. . $^{4,10,25}$

The primary limitation of the study was that, since it was conducted in a tertiary-care hospital set-up, chances of high-risk cases may be more, and it may not truly reflect the prevailing situation in a community setting.

\section{CONCLUSION}

The present study was an analytical study of adolescent pregnancies The present study showed that most of the girls belonged to the older adolescent group. They had poor knowledge regarding contraception and there was poor compliance to antenatal checkups. Anemia, preterm labour, hypertensive disorders of pregnancy and premature rupture of membrane were the major maternal complications. Low birth weight and still births were major adverse fetal outcomes. Adolescent pregnancies put the young girls at risk to many health-related complications and their newborns to poor birth outcomes. Adverse outcome arise not only from physical and medical causes but are also related with familial and socio-cultural factors. A delay in marriage would result in delayed pregnancy and would give the young girls opportunities of education and employment and empower them.

Funding: No funding sources Conflict of interest: None declared

Ethical approval: The study was approved by the Institutional Ethics Committee

\section{REFERENCES}

1. Lawlor DA, Shaw M. Teenage pregnancy rates: high compared with where and when. J Royal Soc Medic. 2004;97:121-3.

2. World Health Organization update 2014
3. Population Reference Bureau. The World's youth 2000. Population Reference Bureau, Washington DC. 2000.

4. Kumar A, Singh T, Basu S, Pandey S, Bhargava V. Outcome of teenage pregnancy. The Indian J Pedia. 2007;74(10):927-31.

5. Trivedi SS, Pasrija S. Teenage pregnancies and their obstetric outcomes. Trop Doct. 2007;37(2):85-8.

6. Cornelius MD, Goldschmidt L, Willford JA, Leech SL, Larkby C, Day NL. Body Size and Intelligence in 6-year-olds: are offspring of teenage mothers at risk? Matern Child Health J. 2009;13(6):847-56.

7. Wellings K, Wadsworth J, Johnson A, Field J, Macdowall W. Teenage fertility and life chances. Rev Reprod. 1999;4:184-90

8. Acharya DR, Bhattarai R, Poobalan A, Van TE, Chapman G. Factors associated with teenage pregnancy in South Asia: a systematic review. Health Sci J. 2010;4:1-13.

9. Kamini S, Avvaru KV. Teenage Pregnancy: Maternal and Fetal Outcomes. IOSR J Dent Medic Sci. (IOSR-JDMS). 2014;13(4):41-4.

10. Rudra S, Bal H, Singh S. A retrospective study of teenage pregnancy in a tertiary care hospital. Int $\mathbf{J}$ Reprod Contracept Obstet Gynecol. 2013;2:383-7.

11. Gollapudi R, Sistla J. Teenage pregnancy: demographics, maternal and foetal outcome. J Evid Based Med Healthc.2016;3(68): 3625-3672.

12. Ganatra B and Elul B. Legal but not always safe: Three decades of a legal abortion policy in India. Gaceta Medica de Mexico. 2003;139:S103-8.

13. Orientation programme for medical officers to provide adolescent reproductive and sexual health services. Facilitators Guide. MoHFW, Govt. of India 2006.

14. Mahfouz AA, El-Said MM, Al-Erian RA, Hamid AM. Teenage pregnancy: are teenagers a high risk group?. Europ J Obstet Gynecol Reprod Biol. 1995;59(1):17-20.

15. Yasmin G, Kumar A, Parihar B. Teenage Pregnancy - its impact on maternal and fetal outcome. Int J Scienti Study. 2014;1(6):9-13.

16. Thaker RV, Panchal MV, Vyas RC, Shah SR, Shah PT, Deliwala KJ. Study of feto-maternal outcome of teenage pregnancy at tertiary care hospital. Gujarat Medic J. 2013; 68( 2):100-3.

17. Brabin BJ, Hakimi M, Pelletier D. An analysis of anaemia and pregnancy-related maternal mortality. J Nutr. 2001;131(2S-2):604S-15S.

18. Prema K, Neel Kumari S, Rama Lakshmi BA. Anaemia and adverse obstetric outcome. Nutr Rep Int. 1981;23:637-43.

19. Santos GH, Martins M da G, Sousa M da S. Gravidez na adolescência e fatores associados com baixo peso ao nascer. Rev Bras Ginecol Obstet. 2008;30(5):224-31.

20. Kongnyuy EJ, Nana PN, Fomulu N, Wiysonge SC, Kouam L, Doh AS. Adverse perinatal outcomes of adolescent pregnancies in Cameroon. Matern Child Health J. 2008;12(2):149-54. 
21. Reime B, Schücking BA, Wenzlaff P. Reproductive outcomes in adolescents who had a previous birth or an induced abortion compared to adolescents' first pregnancies. BMC Pregnancy Childbirth. 2008;8:4.

22. Althabe, F, Moore, JL, Gibbons, L. Adverse maternal and perinatal outcomes in adolescent pregnancies: The Global Network's Maternal Newborn Health Registry study. Reprod Health. 2015;12:S8

23. Yasmin S, Osrin D, Paul E, Costello A. Neonatal mortality of low-birth-weight infants in Bangladesh. Bull World Health Org. 2001;79(7):608-14.
24. Lopoo LM. Labor and delivery complications among teenage mothers. Biodemography Soc Biol. 2011;57(2):200-20.

25. Mukhopadhyay P, Chaudhuri RN, Paul B: Hospitalbased perinatal outcomes and complications in teenage pregnancy in India. $\mathrm{J}$ Health Popul Nutr. 2010;28(5): 494-500.

Cite this article as: Srivastava S, Chandra M, Singh UK. Analytical study of adolescent pregnancies at a tertiary care centre. Int J Reprod Contracept Obstet Gynecol 2017;6:1229-34. 